\title{
BMJ Open Preferences for life-sustaining treatment in Korean adults: a cross-sectional study
}

\author{
HyunChul Youn, ${ }^{1}$ Suk-young Lee, ${ }^{2}$ Han-yong Jung, ${ }^{1}$ Shin-Gyeom Kim, ${ }^{1}$ \\ Seung-Hyun Kim, ${ }^{3}$ Hyun-Ghang Jeong (D) ${ }^{3,4}$
}

To cite: Youn $\mathrm{H}$, Lee $\mathrm{S}$, Jung $\mathrm{H}$, et al. Preferences for life-sustaining treatment in Korean adults: a crosssectional study. BMJ Open 2021;11:e039470. doi:10.1136/ bmjopen-2020-039470

- Prepublication history and additional materials for this paper is available online. To view these files, please visit the journal online (http://dx.doi. org/10.1136/bmjopen-2020039470).

Received 16 April 2020 Revised 30 November 2020 Accepted 02 December 2020

Check for updates

(c) Author(s) (or their employer(s)) 2021. Re-use permitted under CC BY-NC. No commercial re-use. See rights and permissions. Published by BMJ.

${ }^{1}$ Department of Psychiatry, Soonchunhyang University Bucheon Hospital, Bucheon, The Republic of Korea

${ }^{2}$ Division of Hemato-Oncology, Department of Internal Medicine, School of Medicine, Wonkwang University, Gunpo, The Republic of Korea

${ }^{3}$ Department of Psychiatry, Korea University Guro Hospital, Korea University College of Medicine, Seoul, The Republic of Korea

${ }^{4}$ Korea University Research Institute of Mental Health, Seoul, The Republic of Korea

Correspondence to Dr Hyun-Ghang Jeong; jeonghg@korea.ac.kr

\section{ABSTRACT}

Objectives Life-sustaining treatment is any treatment that serves to prolong life without reversing the underlying medical conditions, and includes cardiopulmonary resuscitation, mechanical ventilation, haemodialysis and left ventricular assist devices. This study aimed to investigate the thoughts on life-sustaining treatment of Koreans and to assess the factors associated with deciding to not receive life-sustaining treatment if they develop a terminal disease.

Design Cross-sectional study.

Setting Guro-gu centre for dementia from 1 May 2018 to 31 December 2019.

Participants In total, 150 individuals participated in this study.

Outcome measures The questionnaire consisted of self-report items with some instructions, demographic characteristics, thoughts on life-sustaining treatment and psychosocial scales. The preferences of the participants were investigated on the assumption that they develop terminal cancer. The psychosocial scales included the Generalised Anxiety Disorder-7 (GAD-7), Patient Health Questionnaire-9 (PHQ-9), Connor-Davidson Resilience Scale and Multidimensional Scale of Perceived Social Support (MSPSS).

Results We classified our participants into two groups: individuals who wanted to receive life-sustaining treatment (IRLT) and individuals who wanted to not receive life-sustaining treatment (INLT). There were twice as many participants in the INLT group than there were in the IRLT. In making this decision, the INLT group focused more on physical and mental distress. Additionally, $32.7 \%$ of participants responded that terminal status was an optimal time for this decision, but more participants want to decide it earlier. The GAD-7 and PHQ-9 scores were significantly higher in the INLT group than in the IRLT group. However, the INLT group had significantly lower MSPSS family scores.

Conclusion Our findings can help assess issues regarding advance directives and life-sustaining treatment, and will be a reference for designing future studies on this issue.

\section{INTRODUCTION}

According to the constitutional right to selfdetermination, judging one's own life is part of one's dignity and worth as a human being. ${ }^{1}$ In this respect, there has been much discussion of the right to decide one's own life at the last moment of life. ${ }^{1}$ Landmark
Strengths and limitations of this study

- This study enrolled Korean individuals for assessing issues regarding advance directives and lifesustaining treatment.

- We adopted cross-sectional design, and the questionnaire consisted of demographic characteristics, thoughts on life-sustaining treatment and psychosocial scales.

- The effects of psychosocial factors, including depression, anxiety, resilience and perceived social support on decision for life-sustaining treatment, were investigated.

- Our participants tended to want to not receive lifesustaining treatment, and higher levels of education, depression, and anxiety and lower levels of family support were associated with the decision to not receive life-sustaining treatment.

- Our questionnaire consisted of only self-report items, but using various methods, such as clinicianreport scales and interviews can help avoid misunderstandings of the terms and ensure a more effective survey.

legal decisions on severely injured individuals seeking relief from persistent vegetative states were made in the USA starting around $1990 .^{2}$ At this time, the Patient Self-Determination Act was first formalised in the USA. ${ }^{3}$ In South Korea, the Act on the Determination of LifeLife Care for Patients in the Hospice and Relaxation Medicine and the Deathly Hallows Process was finally passed by the National Assembly on 8 January 2016 and was implemented on 4 February 2018. ${ }^{1}$ Under this act, advance directives can be prepared in South Korea for terminal states where decisionmaking is impossible. Advance directives are defined as 'any statement given in advance of decisional incapacity directing the provision of life-sustaining treatment in incapacitated states'.?

Between February 2018 and September 2019, a total of 378350 people registered their advance directives with the National Agency for Management of Life-Sustaining Treatment. ${ }^{4}$ Of these people, 859 individuals 
died without life-sustaining treatment according to their advance directives. ${ }^{4}$ However, until now, the majority chose to make the decision only at the very end of their lives. Furthermore, the discontinuation of life-sustaining treatment of many people was determined by their family members. The National Agency for Management of Life-Sustaining Treatment ${ }^{4}$ reported that the former numbered 21479 and the latter 22758 over the same time period. Previous studies showed that a majority of people do not want aggressive treatment at the last moment of life. ${ }^{35-8}$ Accordingly, advance directives are especially important because individuals who did not sign advance directives tend to receive aggressive life-sustaining treatment until the last moment of their lives regardless of their own intention. ${ }^{9}$

In this study, we focused on the thoughts regarding lifesustaining treatment of Korean individuals. We believe that our survey may help assess issues surrounding advance directives and life-sustaining treatment in individuals in the early stages of implementation of the advance directives system. In addition, medical illnesses that may be related to fatal conditions can also be comorbid with negative mood. ${ }^{10-13}$ That is, one can experience depression or anxiety at the moment one signs one's own advance directive or decides whether to receive life-sustaining treatment. This study may be additionally helpful in assessing the possibility that negative mood affects the decision regarding life-sustaining treatment.

The aim of this study was to investigate the thoughts regarding life-sustaining treatment of Koreans and to assess factors, especially negative mood, associated with not receiving life-sustaining treatment if they develop a terminal disease.

\section{METHODS}

\section{Participants and procedure}

A total of 152 Korean individuals participated in this study. We recruited family members of visitors in Guro-gu centre for dementia from 1 May 2018 to 31 December 2019. We invited 170 individuals, but 18 people declined to participate in this study because they were not interested in the issue of the research. Participants with a history of serious disease, such as cancer, myocardial infarction and cerebrovascular diseases were excluded from the study. After some instructions were provided, participants filled out a survey on the spot. It took about 20-30 min to complete the questionnaires. Participants answered the questions anonymously. Of the 152 initial participants, 2 had missing core questions (for thoughts on life-sustaining treatment) and were, therefore, excluded. Before completing the questionnaires, participants were informed about the study protocol and gave their written informed consent.

\section{Measures}

All questionnaires were in self-report format. The questionnaire consisted of three parts. The first part contained items assessing the following demographic characteristics: age, gender, education, marital status, housing status, occupational status, religion and monthly income.

In the second part, participants answered questions regarding their thoughts on life-sustaining treatment. We provided a description of the terms used in the questionnaire before the second part to avoid confusion(online supplemental file 1) (online supplementary data). For example, 'terminal state' is defined as a condition in which treatments for the purpose of life extension are not applicable to patients. We adopted 'terminal cancer' as the example to help participants understand lifesustaining treatment better, because many South Koreans regard cancer as the most worrying disease. ${ }^{14}$

The third part included the psychosocial items. We adopted the Generalised Anxiety Disorder -7 (GAD-7) and Patient Health Questionnaire-9 (PHQ-9) to assess anxiety and depression, respectively. ${ }^{15}$ A higher score on these scales indicates a higher possibility of having anxiety or depressive symptoms. These scales have been translated into Korean, and their reliability and validity have been confirmed. ${ }^{16}{ }^{17}$ The Connor-Davidson Resilience Scale (CD-RISC) was used to assess the degree of resilience. ${ }^{18}$ This scale contains 25 items scored in a fivepoint response format, and the total score ranges from 0 to 100 , where higher scores reflect greater resilience. We used the Korean version of the CD-RISC, which has been found to be reliable and valid. ${ }^{19}$ We included the Multidimensional Scale of Perceived Social Support (MSPSS) to evaluate the perceived social support of family, friends and significant others. ${ }^{20}$ The MSPSS contains four items that are rated on a seven-point scale ranging from very strongly disagree ${ }^{1}$ to very strongly agree. ${ }^{7}$ We adopted the Korean version of MSPSS. ${ }^{21}$

\section{Statistical analysis}

Descriptive statistics were calculated for all variables (ie, means and SDs for continuous variables and percentages for categorical variables). Differences between the individuals who wanted to receive life-sustaining treatment (IRLT) and individuals who wanted to not receive lifesustaining treatment (INLT) groups in terms of basic characteristics, thoughts on life-sustaining treatment, and psychosocial scales were analysed using PASW Statistics 18.0 (SPSS, Chicago, Illinois, USA). We used independent t-tests for continuous variables and $\chi^{2}$ tests or Fisher's exact test for categorical variables.

\section{RESULTS}

According to the answer of the question 'Do you want to receive life-sustaining treatment?', we classified our participants into two groups: IRLT and INLT. Among the 150 participants, the IRLT and INLT groups comprised 50 and 100 participants, respectively. Table 1 shows the basic characteristics of the IRLT and INLT groups. The mean age of participants was $45.38(\mathrm{SD}=14.71)$ years, and $56.0 \%$ were women. The participants with college-level 
Table 1 Basic characteristics of IRLT and INLT groups

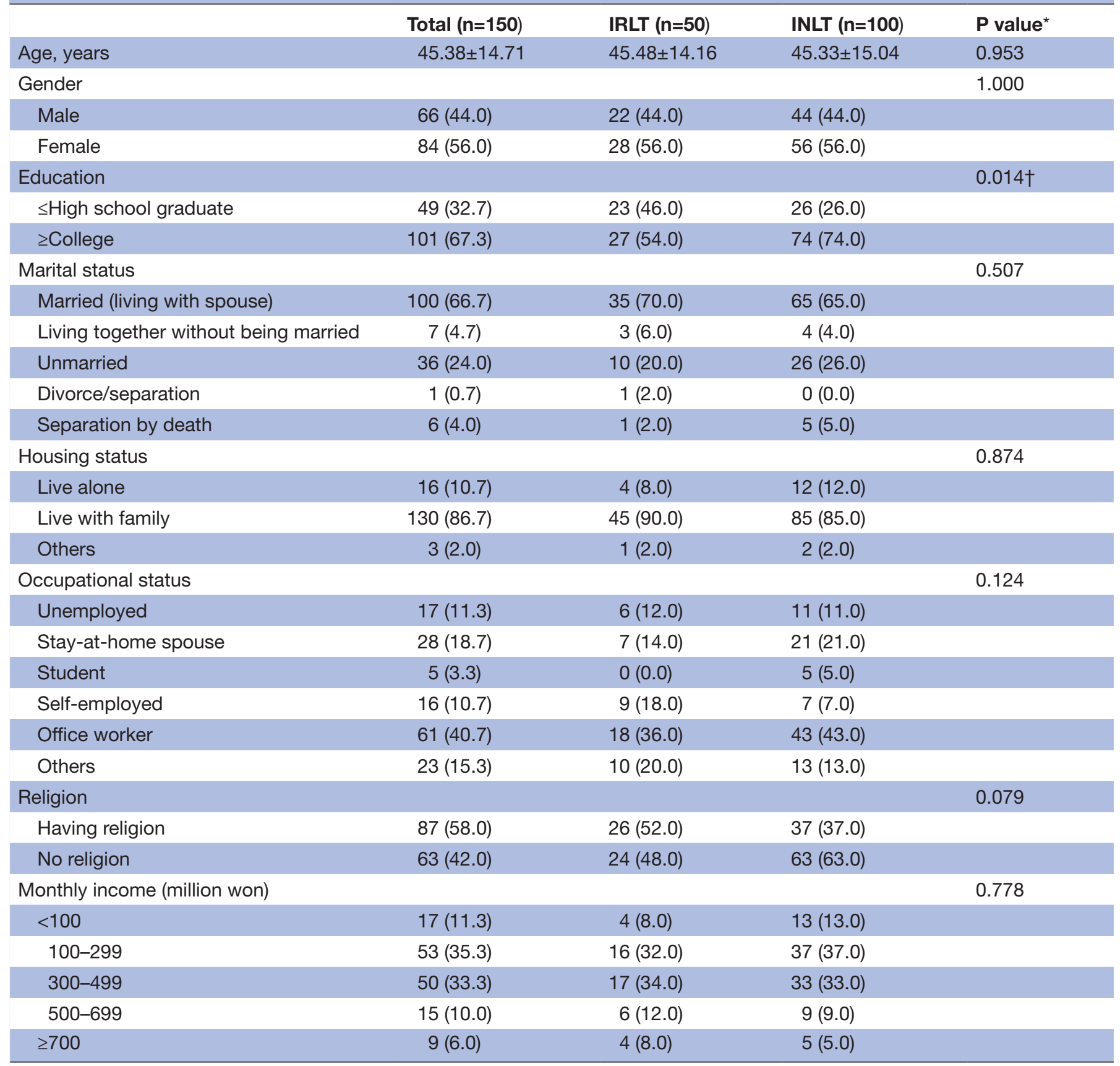

The data is presented as mean \pm SD or number (\%).

${ }^{*} \mathrm{P}$ values were calculated using the $\chi^{2}$ test or Fisher's exact test and independent t-test. $\dagger \mathrm{p}<0.05$.

INLT, individuals who wanted to not receive life-sustaining treatment; IRLT, individuals who wanted to receive life-sustaining treatment.

education or higher were significantly more numerous in the INLT group than in the IRLT group.

We compared the thoughts on life-sustaining treatment of the IRLT and INLT groups (table 2). The IRLT group focused more on the chance of survival, while the INLT group was more concerned about physical and mental distress.

The IRLT and INLT groups also showed differences in some psychosocial scale scores. The GAD-7 and PHQ-9 scores were higher in the INLT group than in the IRLT group, whereas the IRLT group showed significantly higher MSPSS-family scores. These results are shown in table 3 .

\section{DISCUSSION}

In our study, there were twice as many participants in the INLT group compared with those in the IRLT group, who responded that they do not want to receive life-sustaining treatment. Chance of survival was the most important 
Table 2 Thoughts on life-sustaining treatment of IRLT and INLT groups

\begin{tabular}{|c|c|c|c|c|}
\hline & Total $(n=150)$ & IRLT $(n=50)$ & INLT $(n=100)$ & P value ${ }^{\star}$ \\
\hline \multirow{4}{*}{$\begin{array}{l}\text { Most important issue } \\
\text { in deciding whether to } \\
\text { receive life-sustaining } \\
\text { treatment or not }\end{array}$} & Chance of survival (81 (54.0\%)) & $\begin{array}{l}\text { Chance of survival ( } 38 \\
(76.0 \%))\end{array}$ & $\begin{array}{l}\text { Chance of survival ( } 43 \\
(43.0 \%))\end{array}$ & \multirow[t]{4}{*}{$0.001 \dagger$} \\
\hline & Physical distress (29 (19.3\%)) & Physical distress $(3(6.0 \%))$ & $\begin{array}{l}\text { Physical distress (26 } \\
(26.0 \%))\end{array}$ & \\
\hline & Mental distress (13 (8.7\%)) & Religious belief (3 (6.0\%)) & Mental distress (12 (12.0\%)) & \\
\hline & $\begin{array}{l}\text { Other responses (religious } \\
\text { belief, treatment cost) }\end{array}$ & $\begin{array}{l}\text { Other responses (mental } \\
\text { distress, treatment cost) }\end{array}$ & $\begin{array}{l}\text { Other responses (religious } \\
\text { belief, treatment cost) }\end{array}$ & \\
\hline \multirow{4}{*}{$\begin{array}{l}\text { Optimal timing to decide } \\
\text { whether to receive life- } \\
\text { sustaining treatment } \\
\text { (assuming a future } \\
\text { terminal state) }\end{array}$} & Terminal state $(49(32.7 \%))$ & $\begin{array}{l}\text { Immediately after diagnosis } \\
\text { of metastatic cancer }(19 \\
(38.0 \%))\end{array}$ & Terminal state $(37(37.0 \%))$ & \multirow[t]{3}{*}{0.458} \\
\hline & $\begin{array}{l}\text { Immediately after diagnosis of } \\
\text { metastatic cancer }(42(28.0 \%))\end{array}$ & $\begin{array}{l}\text { Immediately after diagnosis } \\
\text { of any cancer regardless of } \\
\text { stage }(13(26.0 \%))\end{array}$ & $\begin{array}{l}\text { Immediately after diagnosis } \\
\text { of any cancer regardless of } \\
\text { stage }(24(24.0 \%))\end{array}$ & \\
\hline & $\begin{array}{l}\text { Immediately after diagnosis of } \\
\text { any cancer regardless of stage } \\
(37(24.7 \%))\end{array}$ & Terminal state (12 (24.0\%)) & $\begin{array}{l}\text { Immediately after diagnosis } \\
\text { of metastatic cancer ( } 23 \\
(23.0 \%))\end{array}$ & \\
\hline & $\begin{array}{l}\text { Other responses (when to } \\
\text { start chemotherapy, during } \\
\text { chemotherapy) }\end{array}$ & $\begin{array}{l}\text { Other responses (when to } \\
\text { start chemotherapy, during } \\
\text { chemotherapy) }\end{array}$ & $\begin{array}{l}\text { Other responses (when to } \\
\text { start chemotherapy, during } \\
\text { chemotherapy) }\end{array}$ & \\
\hline
\end{tabular}

${ }^{*} \mathrm{P}$ values were calculated using the $\chi^{2}$ test or Fisher's exact test. $\dagger \mathrm{p}<0.01$

$\ddagger$

INLT, individuals who wanted to not receive life-sustaining treatment; IRLT, individuals who wanted to receive life-sustaining treatment.

issue in both groups in deciding whether or not to receive life-sustaining treatment, but the INLT group focused more on physical and mental distress. The timing preference order was terminal state, immediately after diagnosis of metastatic cancer and immediately after diagnosis of any cancer regardless of stage in deciding whether to receive life-sustaining treatment. In addition, participants with higher education levels tended to be more common in the INLT group. On the psychosocial scales, the INLT group represented higher levels of depression/anxiety and lower level of perceived family support than the IRLT group.

Most prior studies have reported that the majority of people do not want aggressive treatment in their terminal state. ${ }^{35-8}$ Our results were consistent with these previous studies. In addition, the INLT group rated physical and mental distress highly in deciding their preference for life-sustaining treatment than the IRLT group in this study. According to previous reports, many people want hospice care and a more comfortable process of dying,

Table 3 Comparison of GAD-7, PHQ-9, CD-RISC and MSPSS scores between the IRLT and INLT groups

\begin{tabular}{lcccc}
\hline & Total $(\mathbf{n}=\mathbf{1 5 0})$ & IRLT $(\mathbf{n}=\mathbf{5 0})$ & INLT $(\mathbf{n}=\mathbf{1 0 0})$ & P value $^{*}$ \\
GAD-7 & $4.14 \pm 4.47$ & $3.12 \pm 3.20$ & $4.65 \pm 4.92$ & $0.024 \dagger$ \\
PHQ-9 & $4.99 \pm 5.38$ & $3.88 \pm 4.25$ & $5.56 \pm 5.81$ & $0.048 \dagger$ \\
CD-RISC & $65.33 \pm 17.58$ & $67.76 \pm 17.71$ & $64.09 \pm 17.48$ & 0.237 \\
MSPSS & & & \\
Family & $23.01 \pm 4.88$ & $24.34 \pm 4.04$ & $22.32 \pm 5.15$ & $0.011 \dagger$ \\
Friend & $20.17 \pm 5.01$ & $20.60 \pm 4.26$ & $19.95 \pm 5.37$ & 0.457 \\
Others & $21.61 \pm 5.82$ & $22.76 \pm 5.28$ & $21.02 \pm 6.02$ & 0.086 \\
Total & $64.99 \pm 13.07$ & $67.70 \pm 11.92$ & $63.57 \pm 13.47$ & 0.070 \\
\hline
\end{tabular}

${ }^{*} \mathrm{P}$ value were calculated using independent $\mathrm{t}$-test.

$\mathrm{tp}<0.05$.

CD-RISC, Connor-Davidson Resilience Scale; GAD-7, Generalised Anxiety Disorder-7; INLT, individuals who wanted to not receive lifesustaining treatment; IRLT, individuals who wanted to receive life-sustaining treatment; MSPSS, Multidimensional Scale of Perceived Social Support; PHQ-9, Patient Health Questionnaire-9. 
such as dying in their sleep. ${ }^{622}{ }^{23}$ Some studies have even shown that cancer pain was associated with a desire for hastened death. ${ }^{24}{ }^{25}$ Therefore, we speculate that avoidance of unwanted distress may account for the preference for not receiving life-sustaining treatment. These findings may emphasise the importance of advance directives. A previous study reported a tendency to receive more lifesustaining treatment when patients' intention for lifesustaining treatment was unclear. ${ }^{9}$ Accordingly, more publicity regarding actively participating in registering one's advance directives to National Agency for Management of Life-Sustaining Treatment may be needed to avoid unwanted life-sustaining treatment.

In total, $32.7 \%$ of the participants in our study regarded terminal status as an optimal time to decide whether to receive life-sustaining treatment. However, more participants want to decide it earlier, such as immediately after a diagnosis of metastatic cancer or any cancer regardless of stage. There have been few previous studies with this result. However, Keam $e t a t^{26}$ mentioned that people may regard the decision for life-sustaining treatment as a will that embodies values about end-of-life. We also believe that people may want to make decisions regarding the last moments of their own life, such as by signing advance directives, while they are relatively healthy and physically/mentally intact to preserve their dignity and worth as human beings. However, in determining whether to receive life-sustaining treatment at immediately after a diagnosis of metastatic cancer or any cancer regardless of stage,' it may be important to take into account the possibility that patients are under stress at that time. We speculate that many participants might want to decide on the last moments of their own life earlier than our existing options. For an example, many people would rather prefer to make their decision in a physically and mentally healthy state, uninfluenced by disease or pain. Although we asked the participants to write down other optimal timings directly, most participants opted for one of the existing options. Further studies are needed to clarify this issue.

Among sociodemographic factors, education level was the factor that showed significant differences between the IRLT and INLT groups. That is, participants with higher education levels tended to prefer to not receive life-sustaining treatment in this study. Some previous studies analysed the association between education level and life-sustaining treatment, but the results were controversial. $^{8} 2728$ On the other hand, various studies have reported that individuals with higher education levels had greater interest in advance directives and a stronger tendency to complete them beforehand. ${ }^{6726}$ However, there have been few comments on the causes of this association. ${ }^{6726}$ Though more studies are needed to clarify our results, we speculate that a tendency toward introspection and accessibility of information may account for the association between education level and preference for life-sustaining treatment or advance directives. Our findings may emphasise the necessity of broader publicity and explanations of advance directives for life-sustaining treatment.

In addition, the INLT group showed higher levels of depression and anxiety than the IRLT group. Depressive or anxiety symptoms can be related to hopelessness, worthlessness, frustration, fatigue, irritability, restlessness, feelings of guilt, loss of interest and somatic problems, including pain. ${ }^{29}$ We believe that these symptoms can affect the decision for life-sustaining treatment. For example, as hopelessness is associated with suicide, ${ }^{30-32}$ cancer patients who have feelings of hopelessness might wish to hasten death. In addition, previous studies reported that cancer pain was related to a desire for hastened death. ${ }^{24}{ }^{25}$ Therefore, we speculate that depressive patients with somatic problems, such as pain aggravation might change their minds to select a peaceful death. Similar to our results, Wen et $a l^{33}$ reported that cancer patients with depressive symptoms were more likely to be in the comfort-preferring state in terms of preference for life-sustaining treatment. Our findings suggest that a consideration of depressive and anxiety symptoms may be needed in determining whether or not one receives life-sustaining treatment. For example, clinicians may consider recommending the patient to delay making a decision on life-sustaining treatment if a patient's depressive or anxiety symptoms are believed to be temporary. According to the patient's condition, treatment for depression or anxiety symptoms may be provided to the patient before they make a decision. Our findings may be particularly meaningful because many patients with severe physical illness suffer from depression or anxiety. ${ }^{10-13}$ Future research that can clarify any causal relationship may help verify and advance our results.

Furthermore, participants who felt relatively wellsupported by their family members tended to prefer receiving life-sustaining treatment. However, the results of other studies differ from ours, though a consensus has not been previously reached. Kim and Shin ${ }^{34}$ reported that perceived family support was related to the preference for withdrawal of life-sustaining treatment in communitydwelling elderlies. Choi $e t a l^{35}$ also reported that patients who were single, divorced or bereaved were significantly more likely to reverse life-sustaining treatment decisions to a higher intensity of life-sustaining treatment. As our findings were opposite to these previous studies, consideration of the characteristics of our participants may be needed to understand our results. Our participants were family members of patients in a centre for dementia. Therefore, distress as a family member might be reflected in the answers on MSPSS-family items. That is, the participants who perceived a lower level of family support might be likely to suffer from distress as a family member, and consequently might have a greater tendency to prefer peaceful death. We believe that the influences of family support in deciding whether one receives life-sustaining treatment vary depending on the participants and settings of each study. Uhlmann and Pearlman ${ }^{36}$ even showed that family relationships and preference for life-sustaining 
treatment were not significantly associated in chronically ill, elderly outpatients. Further studies including a greater variety of participants can clarify the association between family support and life-sustaining treatment.

In this study, we investigated the preference for lifesustaining treatment and factors associated with the decision in Koreans. The thoughts regarding life-sustaining treatment of our participants were generally consistent with previous reports on life-sustaining treatment. Depressive and anxiety symptoms may have an effect on this issue. According to our findings, if necessary, adequate interventions may be applied to individuals with negative mood during the decision-making process regarding lifesustaining treatment.

There are some limitations to this study. First, our study has a relatively small number of participants. This may limit the generalisability of our results. Second, our participants are the family members of visitors in Guro-gu centre for dementia. Therefore, specific characteristics of our participants, such as caregiver distress can affect our results. Though these may be more helpful to a specific group, such as individuals with family members with cognitive impairment, further studies including various other groups, such as the general public, caregivers of patients with other diseases, patients with cognitive impairment, physicians and cancer patients may represent more informative results. Third, our study used a cross-sectional design. However, the preference for life-sustaining treatment can change over time. Gallo $e t a \hat{l}^{37}$ also reported that periodic reassessment for planning end-of-life care was needed in their 12-year follow-up study. Fourth, absolute differences in the scores of scales between the two groups were relatively small, although statistically significant. For this reason, there may be limitations to the clinical significance of the results of this study. We believe that further study, including patients with psychiatric problems, such as depression and anxiety, can help derive more clinical meaning. Fifth, this study presented specific options for each question regarding life-sustaining treatment. This may be convenient for the participant, but there is a possibility that the participant's intention was not sufficiently reflected. Finally, our questionnaire consisted of only self-report items. Though we provided descriptions of the meanings of the terms, using various methods, such as clinician-report scales and interviews can help avoid misunderstandings of the terms and ensure a more effective survey.

\section{CONCLUSION}

This study showed the thoughts and associated factors regarding life-sustaining treatment of Korean individuals. Our participants tended to want to not receive life-sustaining treatment. In deciding to not receive lifesustaining treatment, chance of survival and physical/ mental distress were the important issues. A total of 32.7\% of participants responded that terminal status was an optimal time to decide whether to receive life-sustaining treatment. However, many more participants want to decide this issue earlier. Among sociodemographic and psychosocial factors, higher levels of education, depression and anxiety, and lower levels of family support were associated with the decision to not receive life-sustaining treatment. Our findings can help assess issues regarding advance directives and life-sustaining treatment, and will be a reference for designing future studies on this issue.

Contributors HCY, S-YL and H-GJ designed and drafted the manuscript. HCY contributed to acquisition of data. HCY and S-HK, S-YL analysed and interpreted the data. H-YJ and S-GK contributed to interpretation. All authors critically revised the manuscript and gave final approval.

Funding This work was supported by the Choi Shin-Hai Neuropsychiatric Research Fund.

Competing interests None declared.

Patient consent for publication Not required.

Ethics approval The necessary ethical permissions were received from the Institutional Review Board at Korea University Guro Hospital prior to the initiation of the research (2018GR0151).

Provenance and peer review Not commissioned; externally peer-reviewed.

Data availability statement Data are available upon reasonable request. The data that support the findings of this study are available on request from the corresponding author.

Supplemental material This content has been supplied by the author(s). It has not been vetted by BMJ Publishing Group Limited (BMJ) and may not have been peer-reviewed. Any opinions or recommendations discussed are solely those of the author(s) and are not endorsed by BMJ. BMJ disclaims all liability and responsibility arising from any reliance placed on the content. Where the content includes any translated material, BMJ does not warrant the accuracy and reliability of the translations (including but not limited to local regulations, clinical guidelines, terminology, drug names and drug dosages), and is not responsible for any error and/or omissions arising from translation and adaptation or otherwise.

Open access This is an open access article distributed in accordance with the Creative Commons Attribution Non Commercial (CC BY-NC 4.0) license, which permits others to distribute, remix, adapt, build upon this work non-commercially, and license their derivative works on different terms, provided the original work is properly cited, appropriate credit is given, any changes made indicated, and the use is non-commercial. See: http://creativecommons.org/licenses/by-nc/4.0/.

ORCID iD

Hyun-Ghang Jeong http://orcid.org/0000-0002-0318-5069

\section{REFERENCES}

$1 \mathrm{Kim}$ JS. Some improvements of act on decisions on life-sustaining treatment for patients. Law Rev 2019;19:357-80.

2 Ditto PH, Hawkins NA. Advance directives and cancer decision making near the end of life. Health Psychol 2005;24:S63-70.

3 Garrido MM, Balboni TA, Maciejewski PK, et al. Quality of life and cost of care at the end of life: the role of advance directives. J Pain Symptom Manage 2015;49:828-35.

4 National Agency for Management of Life-Sustaining Treatment. Present performance status of withdrawal of life-sustaining treatment, 2019. Available: https://www.lst.go.kr/comm/ monthlyStatistics.do [Accessed 31 Oct 2019].

$5 \mathrm{Kim}$ J, Heo S, Hong SW, et al. Correlates of advance directive treatment preferences among community-dwelling older people with chronic diseases. Int J Older People Nurs 2019;14:e12229.

6 Lee MO, Park J, Park EY, et al. The Korean-advance directive model and factors associated with its completion among patients with hematologic disorders. J Hosp Palliat Nurs 2019;21:E10-16.

7 Hoe DF, Enguidanos S. So help me, God: religiosity and end-oflife choices in a nationally representative sample. J Palliat Med 2020;23:563-7.

8 Yun YH, Han KH, Park S, et al. Attitudes of cancer patients, family caregivers, oncologists and members of the general public toward 
critical interventions at the end of life of terminally ill patients. CMAJ 2011:183:E673-9.

9 Pasman HRW, Kaspers PJ, Deeg DJH, et al. Preferences and actual treatment of older adults at the end of life. A mortality follow-back study. J Am Geriatr Soc 2013;61:1722-9.

10 Thom R, Silbersweig DA, Boland RJ. Major depressive disorder in medical illness: a review of assessment, prevalence, and treatment options. Psychosom Med 2019;81:246-55.

11 Spiegel D. Cancer and depression. Br J Psychiatry Suppl 1996:109-16.

12 Katon W, Lin EHB, Kroenke K. The association of depression and anxiety with medical symptom burden in patients with chronic medical illness. Gen Hosp Psychiatry 2007;29:147-55.

13 Steffens DC, Helms MJ, Krishnan KR, et al. Cerebrovascular disease and depression symptoms in the cardiovascular health study. Stroke 1999;30:2159-66.

14 Health Insurance Review \& Assessment Service. Worrying diseases of the people. Wonju: Health Insurance Review \& Assessment Service, 2016.

15 Spitzer RL, Kroenke K, Williams JB. Validation and utility of a selfreport version of PRIME-MD: the PHQ primary care study. primary care evaluation of mental disorders. patient health questionnaire. JAMA 1999;282:1737-44.

16 Choi HS, Choi JH, Park KH. Standardization of the Korean version of patient health questionnaire- 9 as a screening instrument for major depressive disorder. J Korean Acad Fam Med 2007;28:114-9.

17 Seo J-G, Cho YW, Lee S-J, et al. Validation of the generalized anxiety disorder-7 in people with epilepsy: a MEPSY study. Epilepsy Behav 2014:35:59-63.

18 Connor KM, Davidson JRT. Development of a new resilience scale: the Connor-Davidson resilience scale (CD-RISC). Depress Anxiety 2003;18:76-82.

19 Jung Y-E, Min J-A, Shin AY, et al. The Korean version of the ConnorDavidson resilience scale: an extended validation. Stress Health 2012;28:319-26.

20 Eker D, Arkar H. Perceived social support: psychometric properties of the MSPSS in normal and pathological groups in a developing country. Soc Psychiatry Psychiatr Epidemiol 1995;30:121-6.

21 Shin JS, Lee YB. The effects of social supports on psychosocial wellbeing of the unemployed. Korean J Soc Welf 1999;37:241-69.

$22 \mathrm{Kim} \mathrm{S}$, Koh S, Park K, et al. End-of-life care decisions using a Korean advance directive among cancer patient-caregiver dyads. Palliat Support Care 2017;15:77-87.

$23 \mathrm{Kim}$ S, Hong SW, Kim J. Feasibility of the Korean-advance directives among community-dwelling elderly persons. Holist Nurs Pract 2017;31:234-42.

24 Chochinov HM, Wilson KG, Enns M, et al. Desire for death in the terminally ill. Am J Psychiatry 1995;152:1185-91.
25 Hahn MB, Jones MM, Carron H. Idiopathic pelvic pain. The relationship to depression. Postgrad Med 1989;85:263-6.

26 Keam B, Yun YH, Heo DS, et al. The attitudes of Korean cancer patients, family caregivers, oncologists, and members of the general public toward advance directives. Support Care Cancer 2013;21:1437-44.

27 Yun YH, Kim K-N, Sim J-A, et al. Comparison of attitudes towards five end-of-life care interventions (active pain control, withdrawal of futile life-sustaining treatment, passive euthanasia, active euthanasia and physician-assisted suicide): a multicentred crosssectional survey of Korean patients with cancer, their family caregivers, physicians and the general Korean population. BMJ Open 2018:8:e020519.

28 Emanuel EJ, Fairclough DL, Emanuel LL. Attitudes and desires related to euthanasia and physician-assisted suicide among terminally ill patients and their caregivers. JAMA 2000;284:2460-8.

29 Sadock BJ, Sadock VA, Kaplan RP. Sadock's synopsis of psychiatry: behavioral sciences/clinical psychiatry. Philadelphia, PA: Wolters Kluwer, 2015.

30 Minkoff K, Bergman E, Beck AT, et al. Hopelessness, depression, and attempted suicide. Am J Psychiatry 1973;130:455-9.

31 Beck AT, Brown G, Berchick RJ, et al. Relationship between hopelessness and ultimate suicide: a replication with psychiatric outpatients. Am J Psychiatry 1990;147:190-5.

32 Beck AT, Steer RA, Kovacs M, et al. Hopelessness and eventual suicide: a 10-year prospective study of patients hospitalized with suicidal ideation. Am J Psychiatry 1985;142:559-63.

33 Wen F-H, Chen J-S, Chou W-C, et al. Factors predisposing terminally ill cancer patients' preferences for distinct patterns/states of lifesustaining treatments over their last six months. J Pain Symptom Manage 2019;57:190-8.

$34 \mathrm{Kim} \mathrm{HS}$, Shin SR. The influence of social support among community dwelling elderly and their attitude towards the withdrawal of lifesustaining treatment: a mediating effect of self-esteem. Korean $\mathrm{J}$ Adult Nurs 2017;29:373-81.

35 Choi JJ, Kim SH, Kim SW. [Reversals in decisions about lifesustaining treatment and associated factors among older patients with terminal stage of cardiopulmonary disease]. J Korean Acad Nurs 2019:49:329-39.

36 Uhlmann RF, Pearlman RA. Perceived quality of life and preferences for life-sustaining treatment in older adults. Arch Intern Med 1991;151:495-7.

37 Gallo JJ, Abshire M, Hwang S, et al. Advance directives, medical conditions, and preferences for end-of-life care among physicians: 12-year follow-up of the Johns Hopkins precursors study. J Pain Symptom Manage 2019;57:556-65. 